\title{
The fiasco of evidence-based medicine exposed by the COVID-19 pandemic
}

\author{
Joaquim Couto MD MBA ${ }^{\mathrm{a}}$ and Andrew Miles BMedSci MSc MPhil PhD DSc $(h c)^{\mathrm{b}}$ \\ a General and Vascular Surgeon, Private Practice in Oporto, Portugal \\ b Professor of Person Centred Care \& Co-Director, European Institute for Person Centred Health and Social Care, School of \\ Biomedical Sciences, University of West London UK / Senior Vice President/Secretary General, European Society for \\ Person Centered Healthcare \& Editor-in-Chief, European Journal for Person Centered Healthcare \& Founding Editor, \\ Journal of Evaluation in Clinical Practice (1994-2019) / Honorary Professor of Person Centred Care, Centre for Public \\ Engagement, Joint Faculty of Health, Social Care and Education, St. George's University Teaching Hospital Campus, \\ University of London, UK
}

\section{Keywords}

Algorithms, clinical practice guidelines, COVID-19, evidence-based medicine (EBM), meta-analyses, pathophysiological principles, person-centered care, RCTs, tenets of modern medicine, uncertainty

\section{Correspondence address}

Dr. Joaquim Couto, Av. da Boavista N. 117, Sala 301, 4050-115 Porto, Portugal. E-mail: jsacouto@mac.com

Accepted for publication: 29 June 2020

\section{Introduction}

"The human mind has a high tendency to abandon the hard and rational ways of science and surrender to fantasy” - Rudolph Virchow.

Evidence-based medicine (EBM) was promoted by its protagonists as a new medical paradigm, from a Kuhnian [1] perspective, that would "herald a fundamental shift in the way doctors establish the clinical bases for diagnosis, prognosis and therapeutics" [2,3]. Understanding pathophysiological processes and medical experience were minimized and partly replaced by empirical data obtained by "double blind randomized clinical trials", a tool that EBM elevated to the ultimate source of medical knowledge. Evidence obtained this way would "avoid the need for decades of experience as the only pathway to sound clinical judgment" [2]. Doctors could be fast tracked to wisdom by EBM, avoiding countless nights of study and could dump "out of date textbooks" and "journals that were too disorganized to be useful” [2].

In 1998, Couto denounced the pompous EBM delirium as a "transvestite non-theory". Transvestite because it was dressed up as something that it was not (a new paradigm), and non-theory because its assumptions were absurd [1]. In the same paper, this author pointed out that abandoning the traditional medical disciplinary matrix would deprive medical practice of an essential meaning and epistemological function. Evidence (EBM's evidence) would only submerge physicians in terabytes of ungovernable and meaningless data [3]. Good medicine, as
Miles has pointed out, must be informed by reliable scientific evidence, not based on it $[4,5]$.

\section{COVID-19 and EBM}

The COVID-19 pandemic, with all its uncertainties, has shaken the tenets of modern medicine, particularly of EBM, which we consider responsible for much of the confusion and qualms that have baffled us and contributed to the panic that quickly emerged.

Indeed, the COVID-19 pandemic has demonstrated unquestionably and publicly the limitations of EBM and the disastrous consequences of abandoning pathophysiological principles, mocking the substantial medical experience obtained during a professional life, and subordinating the medical praxis to the tyranny of "the best empirical evidence". What happens when a "new virus" appears and a pandemic is declared? Panic, because there are no meta-analyses and no algorithms!

Doctors that are currently in their prime, and who were therefore trained subsequent to the EBM explosion, start digging for "the best available empirical evidence", only to find that there was none because it is a "new virus" causing a "new disease" that we know nothing about. Panic! a plethora of questions appeared, each demanding an urgent answer. Can the COVID-19 virus be transmitted from person to person? Can it be transmitted through aerosols? What about its survival on surfaces? Do masks prevent the transmission of the COVID-19 virus? Is "shelter-in-place" necessary? Should a strict lockdown be enforced? Who knows? There is no empirical evidence, one way or the 
other, because COVID-19 is a "new disease caused by a new virus”. What to do then?

\section{Evidence-free panic}

Panic is not a good counselor and we know what happened. Governments all over the world started shutting down their economies while studies were being carried out in search of the best empirical evidence. If we refer, though, to well established traditional medical practice, we realize that the COVID-19 is not such an absolute novelty. Coronaviruses have been around for quite a long time and have been associated with common colds and with more lethal varieties such as severe acute respiratory syndrome (SARS) and Middle Eastern respiratory syndrome (MERS). SARS caused an outbreak in 2002-2004 and MERS in 2012 [6,7].

It would be therefore logical to extrapolate from this accumulated knowledge and experience to offer guidelines for the COVID-19 pandemic. Person to person could be expected (confirmed), transmission through aerosols or respiratory droplets also expected (confirmed), as well as from fomites (some surfaces). Masks would be recommended for infected people and, of course, mandatory for healthcare personnel, but would not be recommended for healthy people in open spaces. Shelterin-place for healthy people and strict lockdowns would not be considered necessary.

This is exactly what most senior doctors, who have lived through many epidemics and pandemics recommended, but their voices were muffled in the media, if not censored outright by those that were waiting for "the best empirical evidence”. Take, for example, Dr. Knut Wittkowski, who in a recent interview [8] pointed out that only retired people were speaking out against the radical and unnecessary lockdown measures to deal with the COVID-19 pandemic because they were not dependent on institutional salaries or government money. We agree, but think there is also a generational gap that needs to be considered.

\section{EBM: empty handed for COVID-19}

Senior doctors were trained in the classical medical tradition and resort to well established principles to guide their practices and recommendations. Younger generations are a lot more focused on EBM and depend on available evidence to charter their praxis. Seniors had a wealth of medical knowledge and experience to draw from, the EBM believers were empty handed for COVID-19. While radical measures were being enforced, ignorance fuelled by the absence of "the empirical evidence" was behind a series of miscalculations that cost the lives of tens of thousands of people, especially those most vulnerable to the complications of infection. We consider here two scenarios.

The first scenario relates to seniors diagnosed with COVID-19 who were returned to their nursing homes and who contaminated their fellow residents. Returning an infected senior to a nursing home, as occurred in New York under the policies of Governor Cuomo, was an error of such magnitude that it stuns common sense. Exactly the same occurred in the UK $[9,10]$. What type of evidence is required to prevent that catastrophe? An eighteenth century doctor would be revolted to hear about something like this.

The second scenario concerns the blatant disregard for the dire health consequences of the shelter-in-place and severe lockdown policies. When doctors recommend a treatment, its consequences have to be weighed against any drawbacks. Remember the Hippocratic aphorism: Primum non nocere (first, do no harm). Any benefits of a "possible flattening of the curve" by enacting policies such as these would have to be weighed against their well-recognised adverse consequences: depression, suicides, addictions, domestic violence, etc. Also, the cost of withholding the treatment of non-COVID-19 patients has to enter the equation. Patients with cardiovascular and oncological conditions have been terribly and cruelly ignored during this pandemic. A forthcoming paper in the Journal by Miles and Asbridge [11] sets out in considerable detail the short, medium and long-term clinical impacts of the social and political mismanagement of COVID-19.

\section{Conclusion}

The double blind randomized clinical trial is a valuable tool and should be employed whenever possible, but randomized controlled trials are not the ultimate source of knowledge and can never replace sound medical knowledge and experience [12]. This becomes vividly obvious when a situation is encountered for which there is no available evidence, but one which demands immediate action such as the emergence of a novel coronavirus. PubMed and Google Scholar have enormous uses, but we still keep our “outdated” Schwartz's Principles of Surgery, Washington Manual, and various "disorganized” journals at hand. Thinking that a "wise and experienced" physician can be produced by EBM was ludicrous from the start, but after the COVID-19 pandemic it has become a positively delusional proposition.

Empirical evidence, like GPS, is a great tool, but only a fool would take his eyes of the road and trust the maps blindly. People that have done it are known to have fallen off precipices and it is our view that this is what has happened during this pandemic: while searching for nonexistent evidence we allowed ourselves to take decisions that drove us off a precipice and we have without doubt seen that the so called cure has been worse than the disease itself. Let us all take a deep breath, recognize the missteps, and return to traditional medical reasoning and practice, which remain the basis of an authentic person-centered healthcare [13-17].

\section{Conflicts of Interest}

We declare no conflicts of interest. 


\section{References}

[1] Couto, J.S. (1998). Evidence-based Medicine: a Kuhnian perspective of a transvestite non-theory. Journal of Evaluation in Clinical Practice 4 (4) 267-275.

[2] Sackett, D.L. \& Rosenberg, W.M.C. (1996). On the need for evidence-based medicine. Journal of Public Health 17 (3) 330-334.

[3] Sackett, D.L., Rosenberg, W.M.C., Gray, J.A., Haynes, R.B. \& Richardson, W.S. (1996). Evidence-based Medicine: What it is and what it isn't. British Medical Journal 312 (7023) 71-72.

[4] Miles, A. \& Loughlin, M. (2011). Models in the balance: evidence-based medicine versus evidenceinformed individualised care. Journal of Evaluation in Clinical Practice 17 (4) 531-536.

[5] Miles, A. (2017). From evidence-based to evidenceinformed, from patient focused to person-centered - the ongoing 'energetics' of health and social care discourse as we approach the Third Era of Medicine. Journal of Evaluation in Clinical Practice 23 (1) 3-4.

[6] Gilbert, G.L. (2020). SARS, MERS and COVID-19 new threats, old lessons. International Journal of Epidemiology 49 (3) 726-728.

[7] Peeri, N-C., Shrestha, N., Rahman, S., Zaki, R., Tan, Z., Bibi, S., Baghbanzadeh, M., Aghamohammadi, N., Zhang, W. \& Haque, U. (2020). The SARS, MERS and novel coronavirus (COVID-19) epidemics, the newest and biggest global health threats: what lessons have we learned? International Journal of Epidemiology 49 (3) 717-726.

[8] https://www.spiked-online.com/2020/05/15/we-couldopen-up-again-and-forget-the-whole-thing/.

[9] Mathews, A.W. (2020). New York sent recovering coronavirus patients to nursing homes: 'It was a fatal error'. Wall Street Journal. Available at: https://www.wsj.com/articles/new-york-sent-recoveringcoronavirus-patients-to-nursing-homes-it-was-a-fatalerror-11589470773.

[10] Savage, M. (2020). More than half of England's coronavirus-related deaths will be people from care homes. The Guardian. Available at:

https://www.theguardian.com/society/2020/jun/07/morethan-half-of-englands-coronavirus-related-deaths-will-bepeople-from-care-homes.

[11] Miles, A. \& Asbridge, J.E. (2020). The personcentered care of COVID-19. Immediate, medium and longterm considerations for somatic, psychological, existential and spiritual diagnosis, interventions and management. European Journal for Person Centered Healthcare. In Press.

[12] Miles, A. (2007). Science: a limited source of knowledge and authority in the care of patients. Journal of Evaluation in Clinical Practice 13, 545-563.

[13] Miles, A. \& Asbridge, J.E. (2016). The chronic illness problem. The person-centered solution. European Journal for Person Centered Healthcare 4 (1) 1-5.
[14] Miles, A. \& Asbridge, J.E. (2017). Person-Centered Healthcare - moving from rhetoric to methods, through implementation to outcomes. European Journal for Person Centered Healthcare 5 (1) 1-9.

[15] Miles, A. \& Asbridge, J.E. (2019). The NHS Long Term Plan (2019) - is it person-centered? European Journal for Person Centered Healthcare 7 (1) 1-11.

[16] Miles, A. (2020). Person-Centered Care as the New Professionalism - Raising the Bar from the Lower Denominator of Legally Acceptable Regulatory Competence to the Higher Numerator of Clinical Excellence. European Journal for Person Centered Healthcare 8 (1) 1-16.

[17] Asbridge, J.E. (2020). Progress in the conceptual understanding of person-centered health and social care. 'Person Centered Care: Advanced Philosophical Perspectives’. Loughlin, M., \& Miles, A. (Eds.). 2020. London: Aesculapius Medical Press. European Journal for Person Centered Healthcare 8 (1) 17-19. 